\title{
UMA ANÁLISE DE DIREITO COMPARADO ENTRE BRASIL E MÉXICO NAS EXPERIMENTAÇÕES MÉDICAS COM NASCITUROS
}

\author{
A COMPARATIVE RIGHT ANALYSIS BETWEEN BRAZIL AND \\ MEXICO ON MEDICAL EXPERIMENTS WITH UNBORN \\ CHILDREN \\ Janaína Reckziegel ${ }^{1}$ \\ Amalia Patricia Cobos Campos ${ }^{2}$
}

Recebido em: 25/05/2017 Aceito em: 30/10/2017 janaina.reck@gmail.com pcobos@uach.mx
Resumo: Os experimentos médicos realizados nos nascituros é uma questão altamente debatida, cuja complexidade é aumentada quando se realiza no ventre materno pela pouca proteção, gerando debates éticos, jurídicos e morais diferentes das experiências realizadas in vitro. O presente artigo de corte teórico dogmático, analisa os dilemas ético-jurídicos que esta experimentação apresenta e que incorporam grandes desafios para o Biodireito, examinando aspecto doutrinário, jurisprudencial e legislativo, particularmente focando estes aspectos no México e no Brasil. Para realizar a pesquisa nos auxiliamos essencialmente na hermenêutica e na epistemologia jurídica, se utilizando do método comparativo como ferramenta de valor inestimável para se chegar as conclusões válidas.

Palavras-chave: Biodireito. Brasil. Experimentação Médica. México. Nascituros.

Abstract: The medical experiments performed on the unborn are a highly debated issue, the complexity of which is increased when it is carried out in the womb by little protection, generating ethical, legal and moral debates different from the in vitro experiments. The present dogmatic theoretical article analyzes the ethical-legal dilemmas that this experiment presents and that incorporate great challenges for the Biological Right, examining doctrinal, jurisprudential and legislative aspects, particularly focusing on these aspects in Mexico and Brazil. In order to carry out the research, we mainly use hermeneutics and juridical epistemology, using the invaluable comparative method as priceless value tools to arrive at valid conclusions.

Keywords: Biolaw. Brasil. Medical Experimentation. México. Unborn Children.

\section{INTRODUÇÃO}

Para a presente pequisa é, portanto, necessário especificar o âmbito da proteção para o nascituro, particularmente quando se trata de experimentação, isto é derivado do amargo debate quanto à natureza jurídica do mesmo e sua consideração ou não como uma pessoa, cuja determinação depende também da adequada salvaguarda dos seus direitos tão controversos.

Situa-se nos dilemas acarretados pelos avanços tecnológicos e científicos, já que existem cada vez mais pesquisas com o intuito de buscar avanços em técnicas e procedimentos médicos. Tais pesquisas enquadram-se no campo da chamada medicina fetal, sendo chamadas de intervenções fetais. Estes procedimentos são aqueles realizados intra-útero e geralmente tem como função corrigir alterações na saúde do nascituro, bem como prevenir doenças e malformações.

\footnotetext{
${ }^{1}$ Universidade do Oeste de Santa Catarina - UNOESC - Chapecó - Santa Catarina - Brasil

${ }^{2}$ Universidade Autônoma de Chihuahua - Chihuahua - Chihuahua - México
} 
No entanto, estes avanços carregaram consigo questões éticas a respeito dos limites dos procedimentos fetais. Afinal, em que momento a intervenção deve ser realizada? Quais são os direitos do nascituro nesses casos?

Para o desenvolvimento do assunto se dividirá a presente pesquisa em quarto partes: na primeira se abordará o conceito de nascituro e seus direitos; na segunda etapa observar-se-á um panorama legislativo entre o México e o Brasil; no terceiro tópico se pesquisará as experiências intrauterinas em nascituros e ao finalizar a pesquisa no quarto item se tratará da visão jurisprudencial entre o México e o Brasil.

\section{UMA VISÃO DOUTRINÁRIA: NASCITURO}

Para analisar o problema da experimentação médica em nascituros, precisa-se começar a partir da definição de que a doutrina considera como tal, assim, de uma perspectiva etimológica no dicionário de sua autoria nos diz que a palavra latina no exame, que significa que está a nascer e conclui que se refere ao ser humano "como um sujeito de direito que foi concebido" (OSSORIO, 1974, p. 479), mas ainda não nascido. Para o estudo é, portanto, necessário especificar o âmbito da proteção para o nascituro, particularmente quando se trata de experimentação, isto é derivado do amargo debate quanto à natureza jurídica do mesmo e sua consideração ou não como uma pessoa, cuja determinação depende também da adequada salvaguarda dos seus direitos tão controversos.

Numa perspectiva jurídica Ponce (1990), afirma que pode-se encontrar duas posições, que equiparam o nascituro como nascido através de uma ficção jurídica e derivada das ideias de Justiniano e as correntes alemão-pandectistas, que não compartilham de tal equiparação. Monje (2011), por outro lado, alude às várias teorias que tentam analisar a natureza, esta é a teoria da personalidade desde a concepção, a teoria da ficção jurídica, o direito subjetivo sem um assunto ou à capacidade limitada do concebido, no entanto, enfatiza que o que tem a maior aceitação entre as doutrinas é a teoria da situação da inclinação, em que, embora não é dado personalidade porque ele é adquirido com o nascimento, se nasce para todos os efeitos que são favoráveis. É necessário reconhecer que é de fato desta corrente que segue a maioria das ordenações civis sobre os direitos da personalidade, até à data.

No que se refere este debate é pronunciado Dworkin (1994), em seu trabalho interessante o domínio da vida. Uma discussão sobre o aborto, eutanásia e liberdades individuais, neste trabalho o jurista americano procura esclarecer que as posições enfrentadas nesses aspectos não são realmente tão desenroladas, sempre que eles concordam em um ponto essencial: os dois consideram que a vida é um valor intangível, que o autor chama mesmo "sagrado" (DWORKIN, 1994, p. 97). Mas em uma postura aparentemente contraditória para seus postulados originais compilado em seu famoso livro "O domínio da vida", ele conclui afirmando que o embrião antes do nascimento não pode ser considerado como uma pessoa e, portanto, não pode ser titular de direitos, ou como afirma sarcasticamente Vigo e Corral (1994, p. 432): "Os nascituros não tem graves direitos"; pode-se inferir tal afirmação entre outras questões quando ele afirma, aludindo ao famoso precedente Roe vs. 
Wade, que a decisão de Blackmun, que o feto não é uma pessoa constitucional, é apoiado, por "quase todos os juristas responsáveis, incluindo aqueles que criticam politicamente ou academicamente Roe vs. Wade" (DWORKIN, 1994, p. 146-147), e o mais abundante em sua obra precitada nos diz "o aborto é uma perda no início da vida humana. A morte chega antes que a vida a sério começou" (DWORKIN, 1994, p. 233).

$\mathrm{Na}$ frente das posições pontiagudas encontra-se doutrinas como Ventura (2017) que argumenta que é uma pessoa, e que quando fala-se de direitos humanos se deveria considerar aqueles que protegem o nascituro, estabelecendo que eles têm estes direitos.

Almeida (2004, p. 87-104 ) defende que primordialmente o nascituro tem direito à vida, afirmando que a Constituição na defesa da vida não deixa explicito o momento em que ela se inicia, somente é expresso em lei ordinária. Além disso, esta autora declara que mesmo que não houvesse legislação que defendesse este principio o mesmo ainda seria válido, pois se constitui parte do direito natural. No âmbito internacional a proteção à vida do nascituro é defendida pela Convenção Americana dos Direitos Humanos, pelo Pacto de S. José da Costa Rica, além de ter sido objeto das Recomendações n 934/82,1.046/86 e 1.100/89 do Conselho da Europa.

Almeida (2004, p. 87-104 ) alega que o nascituro difere-se da mãe, tratando-se de pessoa biológica e jurídica e por esta razão teria direito à integridade física e a saúde. Nesse sentido a mãe não poderia recusar o uso de determinados medicamentos e procedimentos, pois não caberia a ela dispor da saúde do nascituro.

No mesmo sentido optou Fernandez (2009, p. 97), que afirma categoricamente que "depois que o espermatozoide penetra o óvulo começa a existência da pessoa humana e desde então o embrião deve ser objeto de direitos que a legislação de cada país deve reconhecer", enfatizando a importância de reconhecer tais direitos, que depende da existência de uma tutela adequada não só do nascituro, mas depois, na infância, adolescência e idade adulta (FERNANDEZ, 2009, p. 101).

Em que pese as doutrinas coincidirem independentemente da postura assumida, em que é a ordenação de uma forma ou outra, especialmente em matéria penal e civil, protege o nascituro. Afirma Bujalance (2010), que deve ser da própria legislação civil, penal e administrativa seguindo uma tutela jurídica ao mesmo.

Agora, seguindo as posições que consideram não ter o caráter de uma pessoa, o questionamento seria: então o que é o nascituro?

As respostas são variadas e analisar-se-á a brevidade mais importante. Ponce (1990, p. 33) afirma que a maioria dos autores considera que ele é parte do organismo da mãe e, portanto, carece de existência separada deste, cita a opinião de Álvarez (apud PONCE, 1990, p. 34) para quem não pode ser considerado nem pessoa nem "coisa" e conclui que é "uma esperança do homem que, em seu dia vai nascer para a vida do direito" (ÁLVAREZ apud PONCE, 1990, p. 34). 
Cárdenas (2007, p. 8) considera que "enquanto para a biologia da pessoa humana (Homo)", é o resultado de um processo evolutivo e milenar e para a teologia a pessoa é um ser divino, isto na medida em que "somos todos filhos de Deus", no campo jurídico, a pessoa é a entidade sujeita a direitos legais e imputações. "Legalmente, então, a pessoa é o que queremos que seja" (CÁRDENAS, 2007, p. 8). E acrescenta que o que precisamos é o que ele chama de uma reclassificação jurídica, em que pessoa e coisa não são a única alternativa.

Este é um dilema não resolvido havendo posições confrontadas, e que a legislação não parece dar uma resposta adequada às suas oscilações, consequentemente, impede a devida proteção ao nascituro, particularmente quando se trata de experimentação.

Realmente a pessoa pelo que ela tem vindo a promover na doutrina brasileira ${ }^{3}$ de nascimento, deve ser estabelecida legalmente, já que o estabelecimento dessa categoria para o nascituro pode delimitar claramente o âmbito dos seus direitos e a proteção de sua dignidade, muito embora ainda não seja uma pessoa, mas está no processo de ser, conceito este que já tenha sido coletado pela Legislação Argentina.

\section{O NASCITURO E SUA PROTEÇÃO JURÍDICA: PANORAMA LEGISLATIVO NO MÉXICO E NO BRASIL}

Devido a discussão acima sobre a natureza jurídica do Nascituro, percebe-se que embora haja um consenso da maioria na ausência da personalidade, isso acontece em paralelo com o tutor que pode variar de acordo com a teoria assumida e o grau de permissibilidade de cada Estado, de tal forma que, embora algumas legislações conferem o caráter de pessoa, também encontra-se aquelas que condicionam os seus direitos ao nascimento. Já para outras é considerado como parte do corpo da mãe que tem poderes para aliená-lo e finalmente não se encontrou legislações em que não há nenhum pronunciamento sobre o exposto.

É reconhecido por Gil (2009) que um dos aspectos mais controversos dentro da doutrina científica que estuda o nascituro é a sua natureza jurídica, onde afirma que "Tomar uma posição sobre este importante extremo tem, além de seu âmbito teórico, uma projeção normativa que traduz diretamente a proteção conferida por sistemas jurídicos para o concebido por nascer" (GIL, 2009, p. 91).

Em vista disso, procurar-se-á analisar a legislação em vigor no México e no Brasil, a este respeito, a partir da ordem fundamental. A Constituição Mexicana, não prevê a proteção da vida das pessoas de forma expressa e consequentemente nem do nascituro, que são implicitamente protegidos no primeiro parágrafo do artigo primeiro com o seguinte teor:

\footnotetext{
${ }^{3}$ Lembre-se que foi o jurista brasileiro Freitas que desenvolveu, com base no Código Civil da Prússia um esboço do Código Civil que proteger a personalidade do produto da concepção que estava no útero da mãe. Seu projeto foi adotado pela Argentina e não pelo Brasil. A este respeito ver: CASSE (1994); entre muitos outros.
}

Revista do Direito [ISSN 1982-9957]. Santa Cruz do Sul, v. 2, n. 52, p. 130-145, maio/set. 2017. https://online.unisc.br/seer/index.php/direito/index 
Artículo $1^{\circ}$. En los Estados Unidos Mexicanos todas las personas gozarán de los derechos humanos reconocidos en esta Constitución y en los tratados internacionales de los que el Estado Mexicano sea parte, así como de las garantías para su protección, cuyo ejercicio no podrá restringirse ni suspenderse, salvo en los casos y bajo las condiciones que esta Constitución establece. ${ }^{4}$ [...] (ESTADOS UNIDOS MEXICANOS, 1917, p. 12).

Esta proteção expressa encontra-se nas constituições de algumas entidades federais que contenham explicitamente tal proteção desde o momento da concepção, as reformas para tal consagração foi discutida em várias controvérsias constitucionais que foram resolvidas pelo Supremo Tribunal de Justiça da Nação.

Ao contrário da Constituição Mexicana, na Constituição Brasileira, o direito à vida é expressamente consagrado no artigo $5^{\circ}$, com o seguinte teor: "Todos são iguais perante a lei, sem distinção de qualquer natureza, garantindo-se aos brasileiros e aos estrangeiros residentes no País a inviolabilidade do direito à vida, à liberdade, à igualdade, à segurança e à propriedade [...]" (BRASIL, 1988).

Igualmente se manifesta Laurentis (2015, p. 40), "considera um delito manipular geneticamente células germinais humanas e intervê material genético humano in vivo", salvo se for para tratar afecções congênitas. Por conseguinte, se encontrou uma proteção mais clara e diligente na Constituição Brasileira em relação ao ponto em análise, embora seja verdade que as questões de experimentação são objeto das leis ordinárias que serão analisadas, acredita-se que a reforma constitucional mexicana que eliminou a vida da tutela é expressamente um desastre. A legislação ordinária lida com a figura particularmente nos códigos civis, cuja evolução foi, logicamente, ao mesmo tempo como os debates estabelecidos em termos de valor da vida e sua possibilidade de disposição; assim, o Código Civil Federal no México, em seu artigo 22 determina:

La capacidad jurídica de las personas físicas se adquiere por el nacimiento y se pierde por la muerte; pero desde el momento en que un individuo es concebido, entra bajo la protección de la ley y se le tiene por nacido para los efectos declarados en el presente Código ${ }^{5}$ (CONGRESSO DA UNIÃO, 1928).

\footnotetext{
${ }^{4}$ Artigo 10. Nos Estados Unidos Mexicanos, todas as pessoas gozam dos direitos humanos reconhecidos desta Constituição e nos tratados internacionais dos quais o estado mexicano seja parte, bem como as garantias para sua proteção, o exercício do que não pode ser restringido ou suspenso, exceto nos casos e nas condições que esta constituição estabelece [...]. (Tradução pelas autoras).

${ }^{5}$ Artículo 22. A capacidade jurídica das pessoas singulares é adquirida pelo nascimento e perde-se com a morte; Mas desde o momento em que um indivíduo é concebido, entra sob a proteção da lei e nasce com ele, para os fins declarados no presente código (Tradução pelas autoras).
} 
Quanto à legislação ordinária diferente para o nascituro, seu regulamento é reduzido para a penalização ou a descriminalização do aborto, nos respectivos sistemas penais e em relação a experimentação, a Lei Geral de Saúde do México, determina no artigo 314 que é considerado como o embrião "para o produto da concepção deste e até o final da décima segunda semana gestacional que em sua fração oitava" (ESTADOS UNIDOS MEXICANOS, 1984, p. 121), na fração de IX, o "produto da concepção da décima terceira semana de idade gestacional para a expulsão do seio materno" (ESTADOS UNIDOS MEXICANOS, 1984, p. 122) será feto; Os preceitos relacionados com a experimentação serão analisados na seção subsequente. A parte de legislação ordinária brasileira da Lei $n^{\circ} 10.406$, de 10 de janeiro de 2002, que determina em seu artigo $2^{\circ}$ : "A personalidade civil da pessoa começa do nascimento com vida; mas a lei põe a salvo, desde a concepção, os direitos do nascituro" (BRASIL, 2002).

Como é simples de observar a legislação civil brasileira expressamente salvaguarda os direitos dos nascituros desde o momento da concepção, analogamente como faz sua contraparte mexicana.

Em matéria de direito penal, como no México, o aborto é penalizado exceto as exceções expressamente estabelecidas na lei, sendo uma questão muito debatida em ambos os países. Aguiar (2016) afirma que:

\footnotetext{
Vale ressaltar que, o nascituro pode ser considerado como um "sujeito de direito", tanto que este é protegido pelo Código Penal, em seus artigos 124 e 127, os quais tratam da matéria referente ao crime de aborto. Este é um exemplo clássico, que comprova seus direitos, uma vez que é ilegal a prática do aborto, exceto as causas excludentes, também previstas neste diploma legal.
}

No que se refere o Regulamento no campo de experimentação, há algumas disposições para serem analisadas na seção subsequente.

\section{EXPERIÊNCIAS CIENTÍFICAS INTRAUTERINAS EM NASCITUROS}

Experimentos médicos é uma questão controversa que sempre gera abordagens éticas importantes, porque, enquanto o benefício do mesmo é inegável, os abusos que foram cometidos em nome de avanços na ciência também têm sido evidenciados, é por isso que o papel do biodireito na regulação desta experiência é essencial.

As condições básicas da experimentação são estabelecidas nas respectivas ordenações, sendo o consentimento informado e a dignidade humana condições sine qua non para permitir a sua realização. 
No presente assunto, dilemas éticos são agravados pela situação do nascituro ser o "objeto" da experimentação, que não pode expressar qualquer consentimento e existem debates sérios sobre se pode falar neste caso de dignidade humana.

A este respeito pode-se começar a citar a recomendação do Europeu n 1.046, de 24.9.86 (CONSEJO DE EUROPA, 1986), onde estabelece que o embrião humano e o feto devem se beneficiar em todas as circunstâncias de respeito pela dignidade humana, bem como no anexo A, sob o título para fins de diagnóstico, no que se refere o presente estudo, que determina:

i. Solo será legítima la intervención sobre un embrión vivo in utero o in vitro, o sobre un feto vivo in utero en el exterior del útero con fines diagnósticos distintos de los previstos en la legislación nacional si tiene como finalidad el bienestar del niño que va a nacer y el favorecer su desarrollo (CONSEJO DE EUROPA, 1986, p. 349).

Em outra ordem de ideias, alínea b da mesma recomendação sob o título de fins terapêuticos estabelece que:

i. Solo se autorizará terapia sobre embriones in vitro o in utero o sobre los fetos in utero para las enfermedades de embriones que presenten un diagnóstico muy preciso, un pronóstico grave o muy serio sin otra solución de tratamiento y, cuando la terapia ofrezca garantías razonables de solución con éxito de la enfermedad.

ii. É proibido manter artificiais embriões ou fetos vivos a fim de obter elementos utilizáveis (CONSEJO DE EUROPA, 1986, p. 350).

Como se observa a declaração visa limitar a experimentação com nascituros para fins de diagnósticos terapêuticos e até mesmo propõe à elaboração de uma lista de doenças que indica que a tendência é no sentido de uma investigação restrita e a certa altura nos leva à existência de uma legislação rigorosa que impede manipulações genéticas e outras questões igualmente debatidas.

A Legislação Mexicana a este respeito é escrita em duas ordenações essenciais, a Lei de Saúde Geral e o Regulamento da Lei Geral de Saúde. O primeiro mencionado, regula a experimentação com seres humanos, essencialmente no artigo 100, que versa o seguinte teor:

Artigo 100. Pesquisa em seres humanos será desenvolvida de acordo com as seguintes bases: I. Deve ser adaptada aos princípios éticos e científicos que justificam a pesquisa médica, especialmente no que se refere a sua possível contribuição para a solução de problemas de saúde e o desenvolvimento de novos campos da ciência médica; II. Pode ser efetuado somente quando o conhecimento a ser produzido não pode ser obtido por outro método adequado; III. Pode ser transportado para fora apenas onde 
há uma garantia razoável que não expõe o assunto em experimentação a riscos desnecessários ou danos; IV. O consentimento por escrito do assunto em que a investigação está a ser realizada, ou de seu representante legal no caso da incapacidade jurídica da pessoa, deve ser esclarecido, uma vez que ele entendeu os objetivos da experimentação e as possíveis consequências positivas ou negativas para a sua saúde; V. Só poderá realizar por profissionais da saúde em instituições médicas que atuem sob vigilância das autoridades sanitárias competentes; A realização de estudos genéticos na população deverá fazer parte de um projeto de pesquisa; 6 VI. O profissional responsável suspenderá a investigação em qualquer momento, se perceber o risco de lesões graves, incapacidade, morte do sujeito em que se realiza a pesquisa; ${ }^{7}$ VII. É responsabilidade da instituição de atenção a saúde proporcionar atenção médica ao sujeito que venha sofrer algum dano, se este for relacionado diretamente com a investigação, sem prejuízo da indenização que legalmente corresponda; e VIII. Os outros que estabelecem os regulamentos correspondentes (ESTADOS UNIDOS MEXICANOS, 1984, p. 49). ${ }^{8}$

O artigo defende os requisitos básicos que devem ser cumpridos a fim de realizar a experimentação com seres humanos, entre os quais estão o consentimento informado e os princípios da bioética de caridade e não maleficência, no entanto, é possível perguntar se é possível enquadrar esses pressupostos para os nascituros. Diante do exposto, a resposta é negativa, pois como já mencionado anteriormente na Lei Geral de Saúde do México, no artigo 134 realiza uma série de definições, estabelecendo o que se entende por feto e embrião, entre outros, enviando para o ponto da questão. Assim, a lei não faz qualquer menção do objeto de experimentação do presente estudo, e o Regulamento da lei geral de saúde no campo da pesquisa em saúde, que contém algumas disposições explícitas a este respeito.

Em uma seção diversa, referindo-se a maioria do conteúdo do capítulo para a mulher grávida e sua proteção, fazendo menção do Nascituro apenas em dois incisos do artigo 47:

Pesquisa em mulheres grávidas, com benefício terapêutico relacionado à gravidez, eles serão permitidos quando: I. Eles visam melhorar a saúde da mulher grávida com um risco mínimo para o embrião ou feto ou II. Se destinam a aumentar a viabilidade do feto, com um risco mínimo para a grávida (ESTADOS UNIDOS MEXICANOS, 1984, p. 19).

A sua formulação é bastante liberal em termos de investigação, desde que não coloque em perigo a mãe ou o feto, insinuando que tal pesquisa deve ser efetuada após a décima terceira semana de gestação, que é quando a legislação mexicana sobre o assunto considera o produto do feto concepção (ESTADOS UNIDOS MEXICANOS, 1984; ESTADOS UNIDOS MEXICANOS, 1986).

\footnotetext{
${ }^{6}$ Fração reformada DOF 14/07/2008 reformada fração DOF-14/12/2011 e 04/08/2013.

${ }^{7}$ Fração reformada DOF 14-12-2011 e 08-04-2013.

$8 \mathrm{O}$ artigo é traduzido pelas autoras.
} 
Da mesma forma o artigo 52 reforça a proteção, afirmando que: "Fetos serão sujeitos de pesquisa somente se as técnicas e meios utilizados oferecerem a máxima segurança para eles e para a grávida" (ESTADOS UNIDOS MEXICANOS, 1986, p. 21).

Portanto, embora que a legislação faça alusão à "segurança máxima" e o "risco mínimo", estas questões devem ser determinadas pelo investigador, desde que a legislação não estabelece requisitos de supervisão especial e não aparecem assimilar ao nascituro no conceito de humano para fins de experimentação, para a contenção da lei deriva de uma tutela inadequada que tem promovido a amplitude dessa forma de experimentação, sem saber que os benefícios têm sido derivados dele.

Pode-se afirmar que este tipo de experimentação destina-se a um objetivo terapêutico em seu favor, a decisão não tem problemas morais, se uma série de condições é preenchida, tais como a possibilidade de obter um diagnóstico claro e preciso. A necessidade de intervenção na ausência de uma alternativa mais razoável; garantias sensatas de resolução da doença e o consentimento dos pais bem como dos profissionais competentes (VIDAL, 2017).

No Brasil, existe a Resolução $n^{\circ} 466$, do Conselho Nacional de Saúde, contendo as orientações e normas para que as experiências onde os seres humanos estejam envolvidos devem ser ajustadas, Diretriz III, sob o título II, os aspectos éticos da investigação que envolve seres humanos, no que se refere no ponto III.2 Subparágrafo ( $r$ ) nos determina "a necessidade das pesquisas realizadas nas mulheres em idade fértil e em mulheres grávidas, a avaliação dos riscos e benefícios e eventuais interferências com a fertilidade, gravidez, o embrião feto [...]" (2012b). Ele também faz algumas menções de problemas de gravidez, mas quanto o produto da concepção é a única referência que faz e no resto do documento apenas trata da intervenção da Comissão Nacional de ética na pesquisa quando são feitas manipulações neles, ou quando vai aplicar o medicamento a nível fetal.

Este entendimento com relação ao Regulamento Mexicano é focado mais para com aqueles que legalmente já têm o status de pessoas e omite ser mais preciso na proteção do nascituro, a doutrina considerou que, em relação a Declaração Universal de Bioética e Direitos Humanos, há uma postura que Rippel, Medeiros e Maluf (2016) consideram para ser flexível e citam Porto (2013) considerando que é refletida em cinco aspectos: A primeira refere-se a supressão do controle do sistema CEP-CONEP em ensaios clínicos internacionais; A segunda é a exclusão da necessidade de aprovação de pesquisas internacionais pelo país de origem; A terceira a suspensão da obrigatoriedade do ensaio pelo risco de dano e só faz concessão dos que venham a obter mais benefícios; A quarta utilização preventiva do protocolo de dados e/ou o material biológico; E finalmente, o quinto ter estabelecido uma remuneração aos participantes da fase clínica 1 em ensaios de bioequivalência da pesquisa. Como observa-se o que parece se promover a luz da doutrina e para poder avançar com a proteção das pessoas envolvidas na experimentação, em termos gerais, para a proteção dos nascituros.

É relevante mencionar a Resolução no 196/96, do Conselho Nacional de Saúde, II.3: Protocolo de Pesquisa, um Documento com a descrição da pesquisa em seus aspectos 
fundamentais, informações relativas ao sujeito da pesquisa, à qualificação dos pesquisadores e à todas as instâncias responsáveis, a mesma incorpora os princípios básicos da bioética, em seu capítulo III - "Aspectos éticos da pesquisa envolvendo seres humanos" (CNS, 1996), que estabelece os lineamentos da experimentação em seres humanos e no tema deste estudo determinando no inciso III.3 que:

III.3 - A pesquisa em qualquer área do conhecimento, envolvendo seres humanos deverá observar as seguintes exigências:

[...] u) levar em conta, nas pesquisas realizadas em mulheres em idade fértil ou em mulheres grávidas, a avaliação de riscos e benefícios e as eventuais interferências sobre a fertilidade, a gravidez, o embrião ou o feto, o trabalho de parto, o puerpério, a lactação e o recém-nascido; v) considerar que as pesquisas em mulheres grávidas devem, ser precedidas de pesquisas em mulheres fora do período gestacional, exceto quando a gravidez for 0 objetivo fundamental da pesquisa; [...] (CNS, 1996).

O documento anterior se atualizou em 2012 com a Resolução 196/96 versão 2012, mas não existe variação alguma no tema unicamente troca a numeração que passa ao III, incisos s e t (CNS, 2012a).

A Lei de Biossegurança, que é um regulamento do artigo 225 da Constituição Federal e esta lei essencialmente estabelece as normas de segurança e mecanismos de fiscalização para atividades relacionadas aos organismos geneticamente modificados bem como cria a Comissão Nacional de Biossegurança, mas quanto ao presente estudo é apenas no produto de embriões de fertilização in vitro.

Ao analisar a Lei 9.279/96, que se concentra em questões de propriedade industrial, não afeta o estudo aqui exposto porque o que ele contém é a incapacidade de patentear uma parte ou a totalidade de um ser vivo, sem prejudicar a relevância de tais disposições que estão, sem dúvida, buscando preservar a dignidade humana mesmo no que esta em processo de gestação e foi produzido artificialmente.

Levando em conta a análise legislativa ficou claro que é pertinente ambas as legislações, pois são mais adequadamente estruturadas nos limites da experimentação com o nascituro, sendo que a proteção é insuficiente, embora parte dos princípios da bioética de caridade e não maleficência, e isto tem sido evidenciado na prática, mas não é suficiente para a adequada proteção ou manutenção da Recomendação Expressa de Europeu (acima citada) que embora não vincula os países em análise porque são países da América Latina, mas representa em alguns pontos uma orientação desejável como a elaboração de uma lista de doenças restringindo a experimentação com nascituros.

Atualmente no Brasil existe também um Projeto de Lei n 478/2007 ou Estatuto do Nascituro de autoria de Luiz Bassuma e Miguel Martini que propõe a proteção integral ao nascituro que foi 
aprovado em 2010 pela Comissão de Seguridade Social e Família. Este projeto de lei pretende assegurar que todos os seres concebidos, mas ainda não nascidos, sejam considerados pessoas (POTECHI, 2013).

São inseridos neste Projeto de Lei os direitos à imagem, honra, integridade física, vida, herança, convívio familiar, entre outros. Desde o momento da concepção o nascituro é protegido por vias legais, ele é considerado uma pessoa, mesmo que in vitro, e deve ser encarado como tal (POTECHI, 2013).

No que se relaciona ao diagnóstico e intervenções no pré-natal, o projeto assegura que estes procedimentos serão executados, mesmo quando o nascituro não apresentar expectativa de vida extrauterina. Além disso, garante que o diagnóstico pré-natal respeitará o desenvolvimento e a integridade do nascituro, que deverá ser precedido pelo consentimento dos pais e os mesmos deverão estar satisfatoriamente informados. Pelo estatuto é vedado emprego de procedimentos que apresentem riscos desproporcionais desnecessários a gestante e ao nascituro (ESTATUTO DO NASCITURO, 2007).

\section{VISÃO JURISPRUDENCIAL: MÉXICO E BRASIL}

No México, embora anteriormente citado, a Constituição não protege expressamente vida e, portanto, nem a dos nascituros, o Supremo Tribunal de Justiça da Nação interpretando a Carta Fundamental decidiu que seu conteúdo não abarca uma proteção à vida destes últimos. Assim, visto como mais Alto Tribunal Mexicano fez o necessário pronunciamento sobre sua tutela implícita, resolvendo-se as ações de inconstitucionalidade 146/2007 e 147/2007, que foram apresentados antes da discriminalização do aborto no Distrito Federal, no qual ele reconheceu que:

PARA A VIDA DO PRODUTO DA CONCEPÇÃO E SUA PROTEÇÃO DERIVA A CONSTITUIÇÃO POLÍTICA DOS ESTADOS UNIDOS MEXICANOS, DOS TRATADOS INTERNACIONAIS E DAS LEIS FEDERAIS E LOCAIS. Pois se é levado em consideração, por um lado, que o propósito dos artigos 4 e 123, parágrafo (a), frações $V$ e XV e a seção $B$, fração XI, alínea c, da Constituição Política dos Estados Unidos Mexicanos, [...], é a aquisição da saúde e o bem-estar dos seres humanos, bem como a proteção dos direitos da mulher [...] Portanto, a tutela do produto da concepção, [...] que o exame das disposições da Convenção sobre os direitos da criança e o Pacto Internacional sobre direitos civis e políticos, [...], segue estabelecer primeiro a proteção da vida da criança antes e após o nascimento e a segunda, a proteção do direito à vida como um direito inerente à pessoa humana [...], advertindo a proteção da vida humana no plano gestacional, pois só considera o nascido como alguém com vida e pune quem the cause a morte, assim como o produto da concepção não está protegido neste momento [...], se a proteção do direito concluem que a vida do produto da concepção se deriva tanto da Constituição dos Estados Unidos Mexicanos, como dos Tratados Internacionais e das Leis Federais e locais" (MÉXICO, 2002, p. 588).

Posteriormente, o Tribunal reiterou o critério anteriormente inserido na ação de inconstitucionalidade 62/2009.

Revista do Direito [ISSN 1982-9957]. Santa Cruz do Sul, v. 2, n. 52, p. 130-145, maio/set. 2017. https://online.unisc.br/seer/index.php/direito/index 
Outro aspecto em que o Tribunal reconheceu os direitos dos nascituros é na comida, quando então deduz-se a tese de que, sob o título: comida. O nascituro merece a proteção legal e o direito para aqueles que, como uma exceção à regra em um sistema processual aberto, se é demonstrada sua viabilidade (Legislação do Estado de Tabasco), emitiu o Terceiro Tribunal Colegiado do Décimo Circuito o amparo direto 928/2004 em 4 de fevereiro de 2005.

Como pode-se perceber os aspectos em que centrou-se na jurisprudência mexicana não tem nenhuma relevância para este trabalho, que incide sobre os aspectos de outra natureza que afetam a lei criminal e família, mas que de qualquer forma, alcança para a construção de uma proteção adequada em termos de experimentação com os nascituros, embora o primeiro mencionado é essencial para preservar a sua vida.

No Brasil, a situação é diferente, em princípio, cita-se uma resolução que suscitou muita controvérsia, a ADPF 54, que relaciona-se com os critérios suportados pelo Tribunal Brasileiro, em 2012 onde o ponto central do debate é que "se discute a legitimidade ou não da interrupção da gestação na hipótese de fetos anencefálicos". A respeito foi entrado em 2005 com duas ações, onde a primeira delas pela Confederação Nacional dos Trabalhadores na Saúde, na qual se discute a legitimidade ou não da interrupção da gestação na hipótese de fetos e a segunda pelo ProcuradorGeral da República, que o promoveu uma Ação Direta de Inconstitucionalidade registrada abaixo sob $n^{\circ}$ 3.510, na qual se discute a constitucionalidade ou não das normas da Lei n 11.105, de 24.03.2005 - Lei de Biossegurança -, que disciplinam as pesquisas com células-tronco embrionárias. O pedido veiculado na ação é o da declaração de inconstitucionalidade na íntegra do art. $5^{\circ}$ da Lei, para que sejam consideradas ilegítimas tais pesquisas (BARROSO, 2005).

Esta Resolução que permite o aborto por razões eugênicas mencionadas, tem sido causa de amplo debate social e doutrinário, então reconhece o Ministro Marco Aurélio em seu relatório que a questão posta nesta ação de descumprimento de preceito fundamental revela-se uma das mais importantes analisadas pelo Tribunal. É inevitável que o debate suscite elevada intensidade argumentativa das partes abrangidas, do Poder Judiciário e da Sociedade. Com o intuito de corroborar a relevância do tema, faz menção a dois dados substanciais. O Primeiro, até o ano de 2005, os juízes e tribunais de justiça formalizaram cerca de três mil autorizações para a interrupção gestacional em razão da incompatibilidade do feto com a vida extrauterina, o que demonstra a necessidade de pronunciamento por parte deste Tribunal. E segundo, que o Brasil é o quarto país no mundo em casos de fetos anencéfalos. Fica atrás do Chile, México e Paraguai. A incidência é de aproximadamente um a cada mil nascimentos [...] afirmando que:

No caso de gravidez extrauterina, o que representa um estado patológico, a sua interrupção não pode constituir o crime de aborto. Não está em jogo a vida de outro ser, não podendo o produto da concepção normalmente alcançar uma vida própria, para que as consequências dos atos praticados são resolvidos apenas contra a mulher. O feto expulso (para ser caracterizado como um aborto) deve ser um produto não-patológico, fisiológico. Se a gravidez é apresentada como um processo 
verdadeiramente mórbido, para não permitir sequer uma intervenção cirúrgica que pudesse salvar a vida do feto, não se fala sobre o aborto, para cuja existência é necessária a presumida continuação da vida do feto (STF, 2012).

Nesta ocasião se chegou ao consenso ( 8 votos contra 2 votos) para descriminalizar o aborto do feto anencefálico:

FETO ANENCÉFALO - INTERRUPÇÃO DA GRAVIDEZ - MULHER LIBERDADE SEXUAL E REPRODUTIVA - SAÚDE - DIGNIDADE AUTODETERMINAÇÃO - DIREITOS FUNDAMENTAIS - CRIME INEXISTÊNCIA. Mostra-se inconstitucional a interpretação de que a interrupção da gravidez de feto anencéfalo em ser conduta tipificada nos artigos 124, 126 e 128, incisos I e II, do Código Penal (STF, 2012).

Mas esta decisão não afeta o que considera-se uma análise de conteúdo relevante.

Outra decisão do Tribunal de Justiça de São Paulo, TJ-SP - Inteiro Teor. Apelação: APL 10038347820138260053 SP 1003834-78.2013.8.26.0053, se estabelece que a partir da deficiência no feto levaram a investigação de formas alternativas de tratamento intraútero de experimentação e dos recentes avanços no tratamento de recém nascidos portadores de alguma doença ou deficiência, como o caso que decidiu a Corte por ação promovida pela mãe por causa da morte de sua filha Lívia, horas depois do parto, fundamentando de que não houve falha no atendimento ou erro médico, que a morte ocorreu em razão da hérnia diagramática congênita com hipoplasia pulmonar (TJ-SP, 2016).

Esta decisão se foca no pagamento de danos morais, se referindo a questões de experimentação e os avanços dos tratamentos no útero materno, mas como pode-se verificar as decisões antes enunciadas se concentram no assunto, mas não ajudam na proteção desta forma de experimentação no útero materno, bem como a legislação é escassa em relação ao tema. Portanto pode-se concluir que a jurisprudência existente não ajuda na proteção que esta forma de experimentação intraútero demanda ante a igualmente escassa legislação em relação as experimentações com nascituros.

\section{CONCLUSÕES}

A imprecisão da lei ante a configuração então genericamente experimentação que atinge o nascituro no útero, deve-se concluir que não é suficiente nas instalações da beneficência e da nãomaleficência para uma proteção adequada dos direitos destes. É portanto, necessário estabelecer um conceito intermediário entre o que é uma pessoa e o que é uma "coisa", que neste momento bem pode-se denominar de um ser humano em formação.

Tanto a Legislação Mexicana como a Brasileira falam da experimentação em nascituros, mas não regulam com clareza em que situações será permitida, causando insegurança, abusos e deixam a critério do investigador as decisões essenciais ante o silêncio do legislador.

Observou-se que existe atualmente no Brasil o Projeto de Lei no 478/2007 ou Estatuto do Nascituro de autoria de Luiz Bassuma e Miguel Martini que pretende tornar integral a proteção ao 
nascituro, sobretudo no que se refere aos direitos de personalidade. Realça-se, assim, o direito à vida, à saúde, à honra, à integridade física, à alimentação, à convivência familiar, e proíbe-se qualquer forma de discriminação que venha a privá-lo de algum direito em razão do sexo, da idade, da etnia, da aparência, da origem, da deficiência física ou mental, da expectativa de sobrevida ou de delitos cometidos por seus genitores.

Quanto a jurisprudência de ambos os países em análise, as mesmas não ajudam a resolver as lagunas da lei, já que são escassas e realmente não se avoca a experimentação em si, só mencionando-a de maneira colateral.

Resulta em consequência urgente que o legislador tanto no México como no Brasil assumam a sua responsabilidade em relação ao tema e construam uma legislação que verdadeiramente responda a necessidade de uma sociedade em evolução com avanços científicos permanentes e que demanda de uma lei detalhada na forma e nos casos que possam ser utilizada em nascituros estas experimentações científicas, mas ao mesmo tempo abarque a proteção dos direitos destes seres humanos em formação.

\section{REFERÊNCIAS}

AGUIAR, Guilherme Menezes. Direito do nascituro e do embrião no Direito Brasileiro. Maio 2016. Disponível em: <https://jus.com.br/artigos/48679/dreito-do-nascituro-e-do-embriao-no-direitobrasileiro>. Acesso em: 2 maio 2017.

ALMEIDA, S.J.A.C. Bioética e direitos de personalidade do nascituro. Scientia luris, v. 7, p. 87104, 2004.

BARROSO, Luis Roberto. Gestação de fetos anencefálicos e pesquisas com células-tronco: dois temas acerca da vida e da dignidade na constituição. R. Dir. Adm., Rio de Janeiro, v. 241, p. 93-120, jul./set. 2005.

BRASIL. Constituição da República Federativa do Brasil de 1988. Disponível em: <http://www4.planalto.gov.br/legislacao/>. Acesso em: 27 abr. 2017.

Lei n. 9.279, de 14 de maio de 1996. Regula direitos e obrigações relativos à propriedade industrial. Disponível em: <http://www.planalto.gov.br/ccivil 03/Leis/L9279.htm>. Acesso em: 28 abr. 2017.

Lei n. 10.406, de 10 de janeiro de 2002. Institui o Código Civil. Disponível em: <http://www.planalto.gov.br/ccivil 03/LEIS/2002/L10406.htm>. Acesso em: 28 abr. 2017.

Lei n. 11.105, de 24 de março de 2005. Regulamenta os incisos II, IV e V do $\S 1^{\circ}$ do art. 225 da Constituição Federal, estabelece normas de segurança e mecanismos de fiscalização de atividades que envolvam organismos geneticamente modificados - OGM e seus derivados, cria o Conselho Nacional de Biossegurança - CNBS, reestrutura a Comissão Técnica Nacional de Biossegurança - CTNBio, dispõe sobre a Política Nacional de Biossegurança - PNB, revoga a Lei $n^{\circ}$ 8.974, de 5 de janeiro de 1995, e a Medida Provisória n 2.191-9, de 23 de agosto de 2001, e os arts. $5^{\circ}, 6^{\circ}, 7^{\circ}, 8^{\circ}, 9^{\circ}, 10$ e 16 da Lei n. 10.814 , de 15 de dezembro de 2003, e dá outras providências. Disponível em: <http://www.planalto.gov.br/ccivil 03/ Ato2004-2006/2005/Lei/L11105.htm>. Acesso em: 28 abr. 2017.

BUJALANCE, Juan Luis Sevilla. La protección del concebido y no nacido en nuestro derecho. Cuadernos de la Real Academia, p. 1-12, jun. 2010. Disponible en: $<$ http://www.investigadoresyprofesionales.org/drupal/sites/default/files/Protecci\%C3\%B3nConcebidoN 
oNacidoJLSevilla.pdf>. Acceso en: 26 abr. 2017.

CÁRDENAS Héctor A. Mendoza, ¿Embrión persona humana? El caso de México. Revista de Bioética y Derecho, n. 11, p. 3-10, sep. 2007. Disponible en: <http://www.ub.edu/fildt/revista/pdf/RByD11 ArtMendoza.pdf>. Acceso en: 27 abr. 2017.

CASSE, Solange Doyhalçabal. El derecho a la vida del nasciturus en la legislación chilena y comparada. Revista Chilena de Derecho, v. 21, n. 2, p. 307-319, 1994

CNS - Conselho Nacional de Saúde. Resolução 196/96. Diretrizes e Normas Regulamentadoras de Pesquisas envolvendo Seres Humanos. Brasília: CNS, 1996. Disponível em: $<$ https://www.ufrgs.br/bioetica/res19696.htm>. Acesso em: 5 maio 2017.

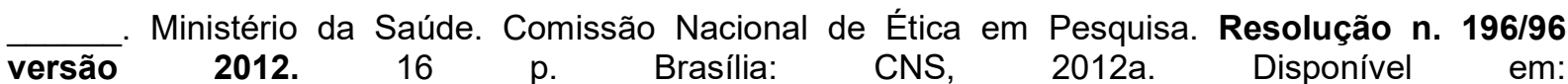
<http://www.pppg.ufma.br/uploads/files/Reslucao\%2019696.pdf>. Acesso em: 5 maio 2017.

Resolução n. 466, de 12 de dezembro de 2012. 12 p. Brasília: CNS, 2012b. Disponível em: <http://conselho.saude.gov.br/resolucoes/2012/Reso466.pdf>. Acesso em: 5 maio 2017.

CONGRESSO DA UNIÃO. Código Civil Federal. Publicado no jornal oficial da Federação em quatro partes, em 26 de maio, 14 de julho, 03 e 31 de agosto. México, 1928.

CONSEJO DE EUROPA. Recomendação núm. 1.046 (1986) de la Assembleia Parlamentaria del Consejo de Europa, relativa a la utilização de embriões y fetos humanos com fines diagnósticos, terapêuticos, científicos, industriales y comerciales. $38^{\circ}$ período de seciones. $p$. 347-350. Disponível em: <https://archivos.juridicas.unam.mx/www/bjv/libros/5/2290/29.pdf>. Acesso em: 5 maio 2017.

DWORKIN, Ronald. El dominio de la vida: una discusión acerca del aborto, la eutanasia y la libertad individual. Trad. R. Caracciolo y V. Ferreres. Barcelona: Ariel, 1994.

ESTADOS UNIDOS MEXICANOS. Constitución Política de Los Estados Unidos Mexicanos. Diario Oficial de La Federación el 5 de febrero de 1917. 295 p. Disponível em: <http://www.diputados.gob.mx/LeyesBiblio/pdf/1 240217.pdf>. Acesso em: 29 abr. 2017.

Ley General de Salud. Nueva Ley publicada en el Diario Oficial de la Federación el 7 de $\begin{array}{llllll}\text { febrero } & \text { de } & 1984 . & 286 & \text { p. } & \text { Disponível }\end{array}$ <http://www.diputados.gob.mx/LeyesBiblio/pdf/142 270117.pdf>. Acesso em: 29 abr. 2017.

Regulamento da Lei Geral de Saúde Pesquisa. Dado en la Residência del Poder Executivo Federal, en la Cidade de México, Distrito Federal, 23 dez. 1986. Disponível em: <http://www.salud.gob.mx/unidades/cdi/nom/compi/rlgsmis.html>. Acesso em: 29 abr. 2017.

ESTATUTO DO NASCITURO. PL $\mathrm{n}^{\circ}$ 478/2007. Disponível em: http://camara.gov.br/proposicoesWeb/prop mostrarintegra?codteor=443584.

Acesso em: 09 setembro, 2017.

FERNÁNDEZ, Dora García. El embrión humano o nasciturus como sujeto de derechos. Revista USCS - Direito, año $X$, n. 17, p. 91-108, jul./dic. 2009. Disponible en: <http://seer.uscs.edu.br/index.php/revista direito/issue/view/97>. Acceso en: 26 abr. 2017.

GIL, Freddy Andrés Hung. Una aproximación crítica al estatuto jurídico del concebido no nacido. Revista del Instituto de Ciencias Jurídicas de Puebla A.C., n. 23, p. 87-112, 2009. Disponible en: $<$ http://www.redalyc.org/pdf/2932/293222963005.pdf>. Acceso en: 26 abr. 2017.

LAURENTIS, Eliane Ferreira de. Questões controversas em família sob a lei de direito do Brasil. Buenos Aires: Augusto Editorial, 2015.

MÉXICO. Ação de Inconstitucionalidade 10/2000. Membros da Assembleia Legislativa do Distrito 
Federal. 29 e 30 de janeiro de 2002, nono Epoch, registro: 187817, plenária, jurisprudência, Judicial semanal da Federação e seu diário, v. XV, fev. 2002, sujeito (s): constitucional, tese: p. / j. 14/2002.

MONJE, María Isabel de la Inglesia. La protección del nasciturus y su proyección en la jurisprudencia civil actual. Revista Crítica de Derecho Inmobiliario, n. 726, p. 2217-2226, jul. 2011. Disponible en: $<$ www.unav.edu/matrimonioyfamilia/observatorio/.../Iglesia RCDI726 Nasciturus.pdf>. Accedo en: 26 abr. 2017.

OSSORIO, Manuel. Diccionario de Ciencias Jurídica, Políticas y Sociales, voz: nasciturus. Heliasta, Buenos Aires, 1974.

PONCE, Lisandro Cruz. El nasciturus. Boletín Mexicano de Derecho Comparado, UNAM, México, año XXIII, n. 67, p. 33-63, ene./mayo 1990. Disponible en: $<$ https://revistas.juridicas.unam.mx/index.php/derecho-comparado/article/view/2675/2931>. Acceso en: 2 feb. 2017.

RIPPEL, Jessica Alves; MEDEIROS, Cleber Alvarenga de; MALUF, Fabiano. Declaração Universal sobre Bioética e direitos humanos e resolução CNS 466/12: análise comparativa. Rev. Bioét., v. 24, n. $3, \quad$ p. $\quad 603-12, \quad$ set./dez. $2016 . \quad$ Disponível em: <http://www.scielo.br/scielo.php?script=sci arttext\&pid=S198380422016000300603\&lng=pt\&tlng=pt>. Acesso em: 20 abr. 2017.

STF - Supremo Tribunal Federal. Arguição de descumprimento de preceito fundamental 54 Distrito Federal. Brasília, 12 de abril de 2012. Ministro Marco Aurélio, Relator, 12/04/2012, Plenário. $433 \quad$ p. Disponível em: $<$ http://redir.stf.jus.br/paginadorpub/paginador.jsp?docTP=TP\&doclD=3707334>. Acesso em: 5 maio 2017.

TJ-SP - Tribunal de Justiça-São Paulo. Apelação cível. Indenização por danos morais. Inteiro Teor. Apelação: APL 10038347820138260053 SP 1003834-78.2013.8.26.0053, 01/09/2016, Ministra Relatora Heloísa Martins Mimessi, $5^{\mathrm{a}}$ Câmara de Direito Público. Disponível em: <https://tjsp.jusbrasil.com.br/jurisprudencia/380320205/apelacao-apl-10038347820138260053-sp-10038347820138260053/inteiro-teor-380320233\#>. Acesso em: 5 maio 2017.

VENTURA, Adán Preito. En torno al nasciturus. p. 273-300. Disponible en: $<$ https://archivos.juridicas.unam.mx/www/bjv/libros/5/2253/15.pdf>. Acceso en: 25 abr. 2017.

VIDAL, María del Carmen. Experimentação com embriões/feto. Revista Bioética e Ciência da

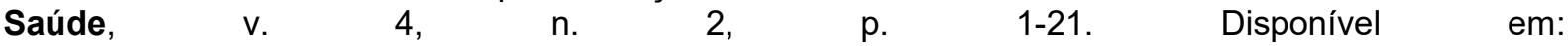
$<$ http://www.bioeticacs.org/iceb/seleccion temas/investigacionEnsayosClinicos/EMBRION.pdf>. Acesso em: 2 maio 2017.

VIGO, Alejandro; CORRAL, Hernán. "Recensión de la obra de Ronald Dworkin: el dominio de la vida: una discusión acerca del aborto, la eutanasia y la libertad individual". Revista Chilena de Derecho, v. 21, p. 431-440, 1994. Disponível em <https://dialnet.unirioja.es/descarga/articulo/2649844.pdf>. Acesso em: 2 maio 2017.

\section{COMO CITAR ESSE DOCUMENTO:}

RECKZIEGEL, Janaína; CAMPOS, Amalia Patricia Cobos. Uma análise de direito comparado entre brasil e méxico nas experimentações médicas com nascituros. Revista do Direito, Santa Cruz do Sul, v. 2, n. 52, out. 2017. ISSN 1982-9957. Disponível em: $<$ https://online.unisc.br/seer/index.php/direito/article/view/9681>. Acesso em: doi:http://dx.doi.org/10.17058/rdunisc.v2i52.9681. 